\title{
Our First Experience of Simultaneous Endovascular Embolization of Proximal Flow-related Aneurysm and Arteriovenous Malfor- mation of the Brain with Liquid Embolic Agent
}

\author{
AA Sufianov ${ }^{1,2}$, SM Karasev ${ }^{1}, R R K_{\text {Khafizov }}{ }^{*}$ and RA Sufianov ${ }^{2}$ \\ ${ }^{1}$ Federal Center for Neurosurgery, Ministry of Health of Russia, Tyumen, Russia \\ ${ }^{2}$ First Moscow State Medical University, IM Sechenov Ministry of Health of Russia, Moscow, Russia
}

*Corresponding author: RR Khafizov, Interventional Radiologist, Federal Center for Neurosurgery, Ministry of Health of Russia, Tyumen, Russia, Tel: +79174360060

\begin{abstract}
Arteriovenous abnormalities of cerebral vessels are quite common. One of the main manifestations of this pathology are arteriovenous malformations. Also, a combination of malformations with aneurysmal expansion of the vascular wall of various localization is not rare. The frequent localization of such aneurysms are afferents going to the malformation site; therefore, such aneurysms are also called proximal flow-related aneurysms. As a rule, a combined approach is used mainly for endovascular treatment of such combined pathologies: Embolization of AVM with a liquid embolic agent and embolization with coils of the cavity of the aneurysm. Cases of embolization of aneurysms with a liquid embolic agent with a very high viscosity are described, but its use for embolization of AVMs is somewhat limited. The use of various embolic materials and additional microcatheters for a combined approach complicates and makes the procedure quite expensive. In addition, it carries a number of possible complications such as: Vasospasm, perforation and thrombosis. We presented a clinical case of simultaneous embolization of AVM and proximal flow-related aneurysm with a liquid embolic agent with a very low viscosity.
\end{abstract}

\section{Keywords}

Arteriovenous malformation, Proximal flow-related aneurysm, Liquid embolic agent

\section{Introduction}

Arteriovenous malformations (AVMs) of the brain are much less common than arterial aneurysms and are observed in 1.3 per 100,000 of the population per year
[1]. One of the most formidable clinical manifestations of arteriovenous malformations (AVM) of the brain is spontaneous intracranial hemorrhage, and is observed with a frequency of $2-3 \%$ of cases per year [2]. According to various sources, the risk of rupture of brain AVM is from 1.2 to $4 \%$ per year [3,4]. Predisposing factors for AVM rupture are a history of AVM rupture, the location of AVMs in the eloquent site of the brain, drainage of AVMs with only a deep vein, the presence of aneurysms in malformations, and the female sex [5]. The peak incidence of AVM occurs at the age of 20-30 years, with a predominance in males $[1,5,6]$. Deep neurological deficit and disability after hemorrhage are noted in 58-81\% of cases [6]. Mortality at AVM breaks is up to $29 \%$ [7]. Clinical manifestations such as epileptic seizures and focal neurological symptoms, mainly due to cerebral blood flow robbing syndrome, are also observed.

AVMs are frequently associated with the presence of intracranial aneurysms (IAs) at a higher incidence compared with the anticipated frequency of each lesion individually. Reported rates of IA identification in association with AVMs have increased due to improvement in diagnostic techniques, particularly 3D and superselective conventional angiography. Intracranial aneurysms may confer a higher risk of hemorrhage at presentation and of rehemorrhage in patients with AVMs and therefore may be associated with a more unfavorable natural history [8-13].

Citation: Sufianov AA, Karasev SM, Khafizov RR, Sufianov RA (2019) Our First Experience of Simultaneous Endovascular Embolization of Proximal Flow-Related Aneurysm and Arteriovenous Malformation of the Brain with Liquid Embolic Agent. Neurosurg Cases Rev 2:027. doi.org/10.23937/2643-4474/1710027 Accepted: October 19, 2019; Published: October 21, 2019

Copyright: (c) 2019 Sufianov AA, et al. This is an open-access article distributed under the terms of the Creative Commons Attribution License, which permits unrestricted use, distribution, and reproduction in any medium, provided the original author and source are credited. 
A)

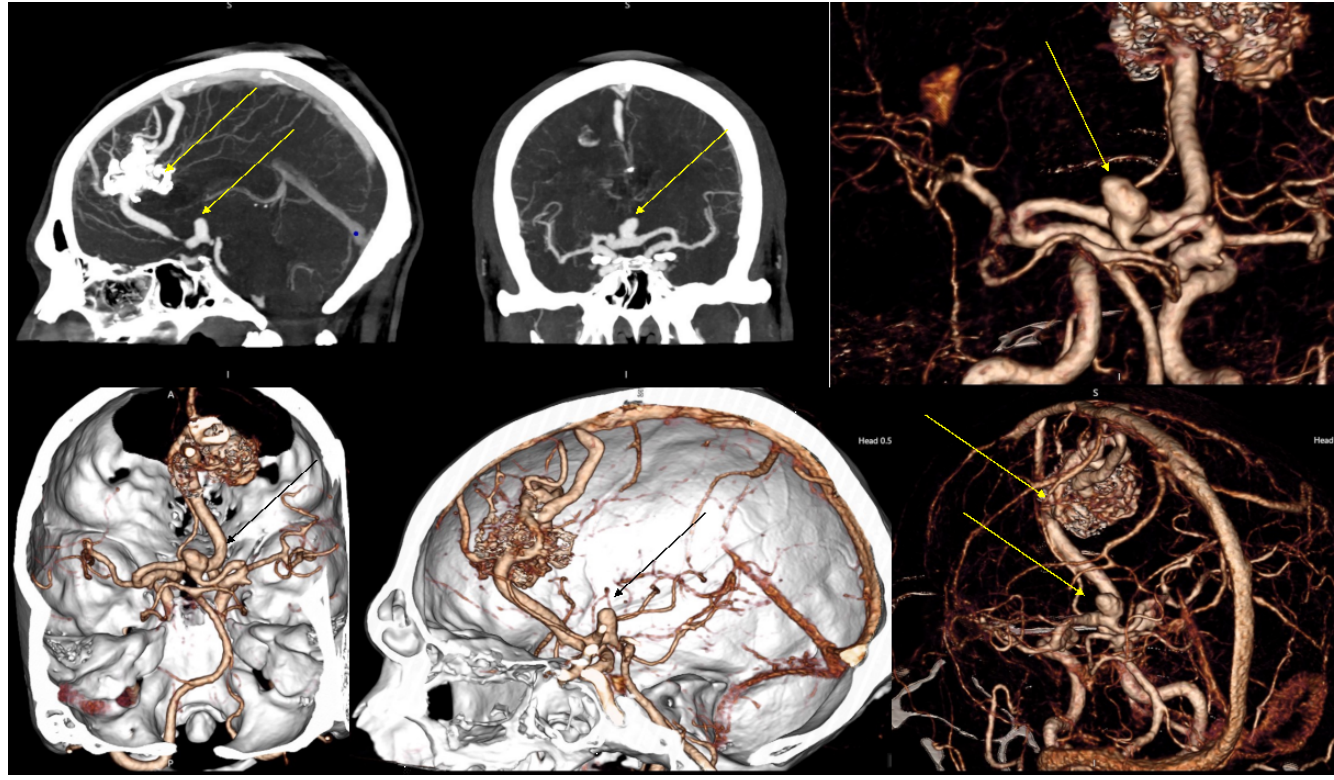

B)

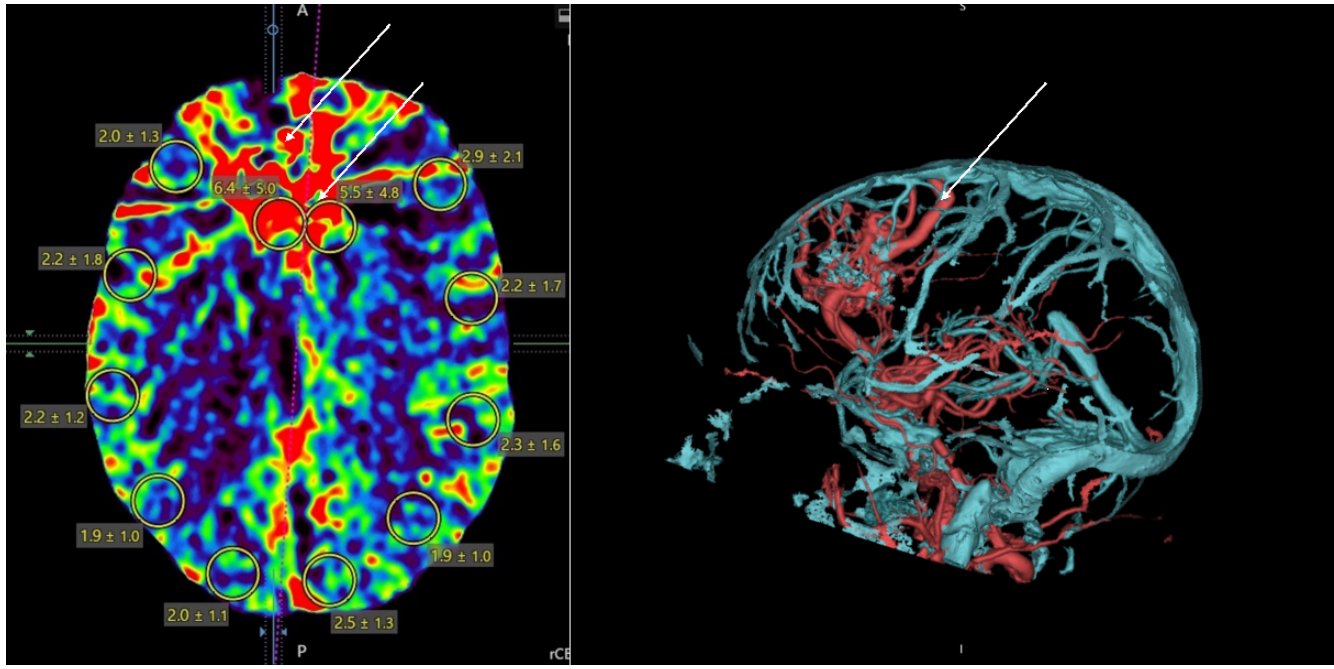

C)
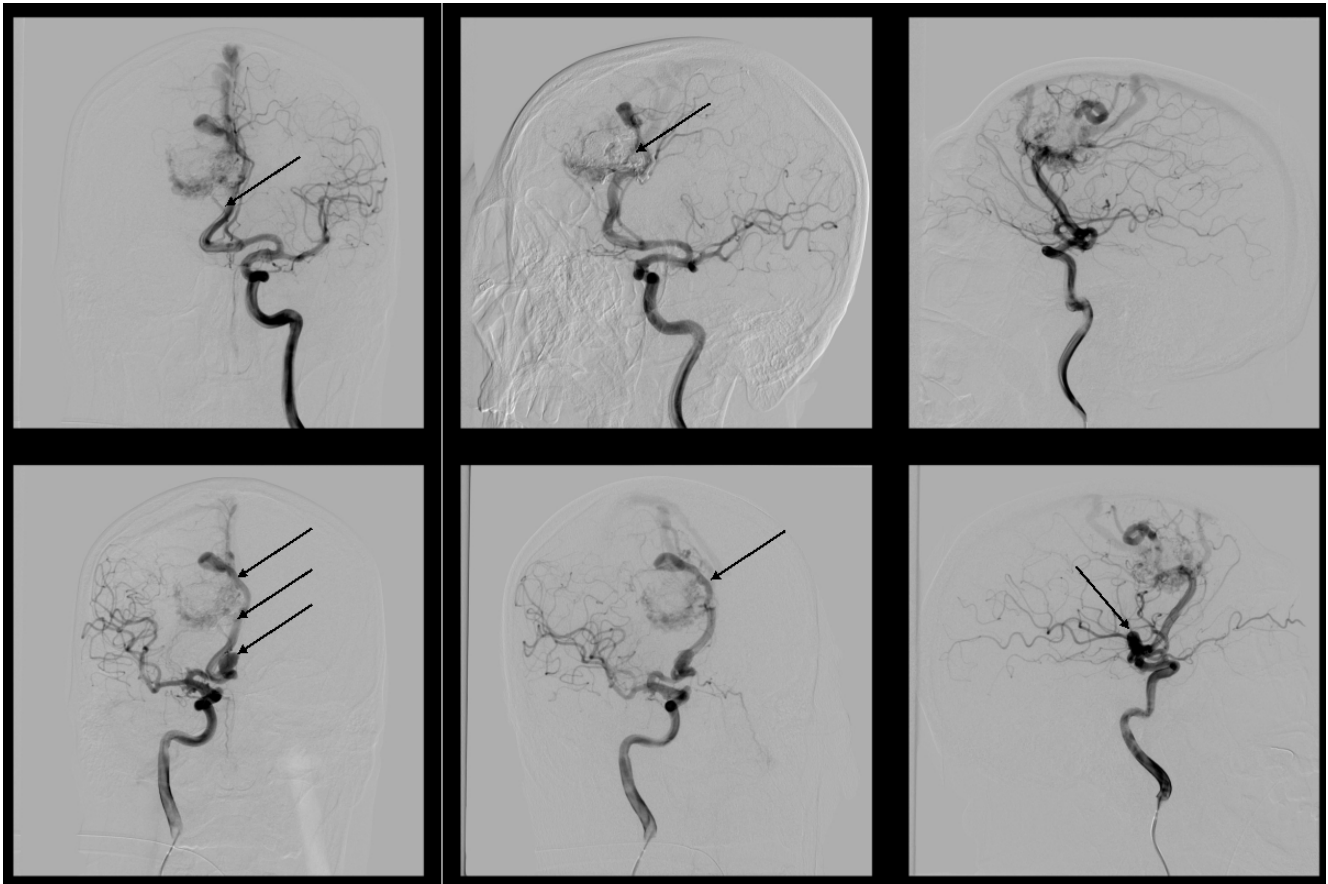

Figure 1: $C T$ - angiography, CT - perfusion and cerebral angiography before endovascular treatment. $1 \mathrm{~A}) \mathrm{CT}$ - angiogram showing AVM and aneurism localization; 1B) CT - prefusion showing hyperperfusion zone in AVM and high-flow drainage vein; 1C) Cerebral angiography showing AVM of the right fronto-parietal region and the proximal flow - related aneurysm on the right terminal ACA afferent. 
No consensus currently exists on the treatment of IAs associated with AVMs. While strong evidence may be lacking, advances in microsurgery, endovascular technology and tech-nique, and radiosurgery have expanded the availability of treatment options. Treatment options need to be weighed to optimize the risk to benefit profile of the intervention based on the expertise and experience of the institution and treating physicians. Reported AVM treatment complication rates are not negligible for surgery $(29 \%$; range, $1.5 \%-54 \%)$, endovas-cular treatment (25\%; range, $7.6 \%-55 \%$ ), and radiosurgery (13\%; range, $0 \%$ $63 \%)$ as observed in a systematic review of ruptured and unruptured AVMs [14] and in the ARUBA study of previously unruptured AVMs (30.7\% complication rate for all treatment modalities) [15].

Any consideration of the treatment of IAs associated with AVMs needs to establish the exact site of rupture in the event of hemorrhagic presentation. The anatomic relationship of IAs and the AVM nidus should be carefully considered when treatment plans are considered. It is of utmost importance to understand whether the source of hemorrhage is the AVM nidus or the IA itself. The diagnosis is made on the basis of clinical experience and inference, and it becomes clearer the farther the hemorrhage is spatially related to the nidus on the head CT scan obtained at presentation [16].

In our case, we present one of the options for endovascular treatment of AVM and aneurysm with a liquid embolic agent in a patient with a previous hemorrhage.

\section{Case Presentation}

Patient V., Male, 41 y.o. Diagnosis: Anomaly of cerebral vessels. Arteriovenous malformation (AVM) in the right fronto-parietal region (Spetzler-Martin 4) with proximal flow-related aneurysm of the right anterior cerebral artery (ACA). Symptomatic epilepsy. Subarach- noid hemorrhage (SAH) 6 months ago. The first stage of embolization with a liquid embolic agent SQUID ${ }^{\circledR} 18$ (BALT) was performed 3 months ago.

In order to determine the tactics of treatment, CT scan - angiography (Figure 1A) with cerebral vascular perfusion (Figure $1 \mathrm{~B}$ ) and selective cerebral angiography (Figure 1C) were performed. An arteriovenous malformation of the fronto-parietal region (Spetzler-Martin 4) was detected with proximal flow-related aneurysm of the right anterior cerebral artery measuring $11.5 \times 7.0 \times 6.0 \mathrm{~mm}$ with the neck size $5.0 \mathrm{~mm}$.

Considering the nature of the AVM and the presence of the proximal flow-related aneurysm, we came to a decision about simultaneous embolization of the AVM and the proximal flow-related aneurysm with a liquid embolic agent $\mathrm{PHIL}^{\circledR} 25 \%$ (MicroVention).

\section{Technique}

Under general anesthesia, the right femoral artery was punctured. An angiographic catheter $5 \mathrm{~F}$ on a guidewire $0.035^{\prime \prime}$ was inserted through the inserted introducer 6F. Catheterized right internal carotid artery (ICA) and was performed cerebral angiography. The angiographic catheter has been replaced with the balloon-tipped guiding catheter Corail $+{ }^{\circledR}$ (BALT) 6 French (F). Installed in the ICA. DMSO - compatible flow-dependent braided microcatheter Sonic ${ }^{\circledR}$ (BALT) $1.5 \mathrm{~F}$ with a tear-off portion of $1.5 \mathrm{~cm}$, is inserted into the right anterior cerebral artery.

Then we inserted a microcatheter into the cervical part of the aneurysm and performed superselective angiography to evaluate the anatomy and the location of healthy vessels (Figure 2).

At the first stage we conducted a microcatheter Sonic ${ }^{\circledR}$ (BALT) $1.5 \mathrm{~F}$ into the AVM performed angiog-

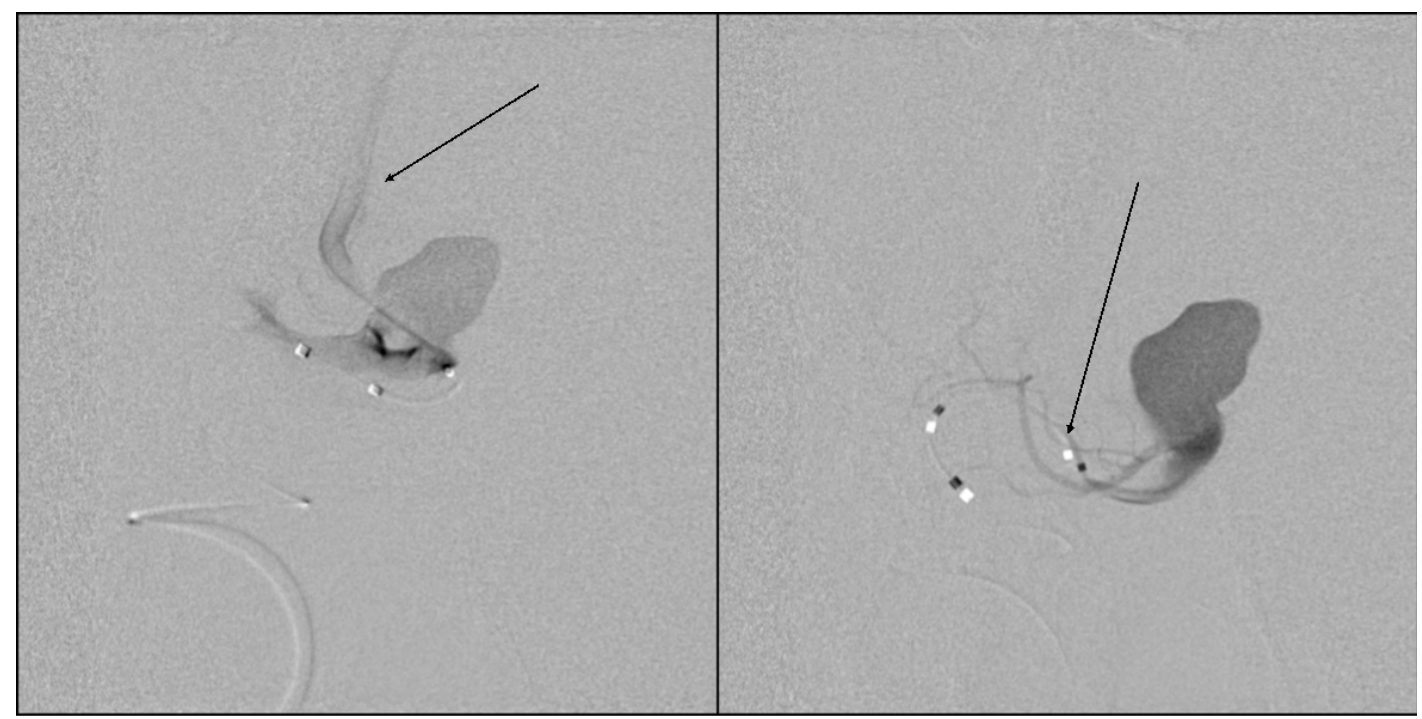

Figure 2: Superselective angiography: Determined by the right recurrent artery of Heubner and normal perforating arteries extending from the aneurism neck. 


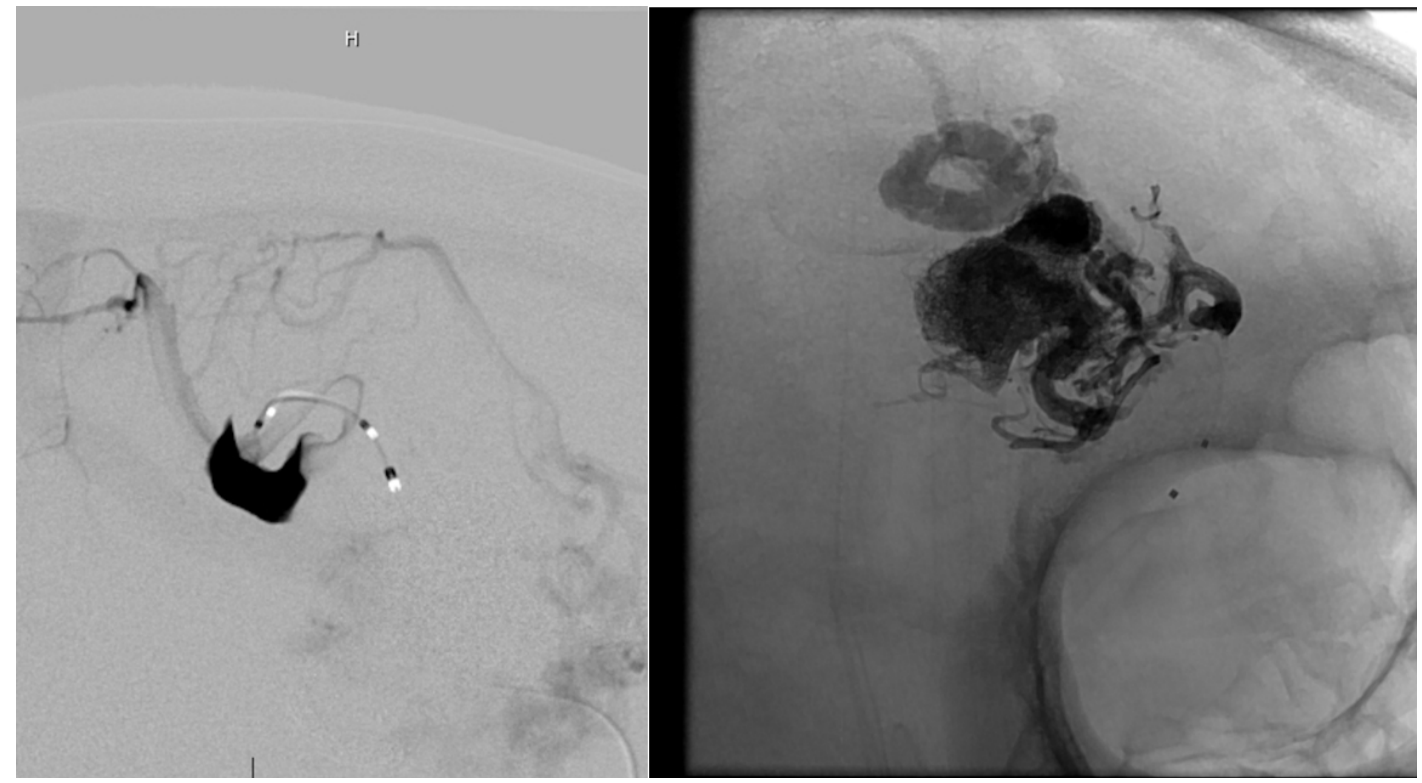

Figure 3: Supreselective angiography showing AVM node and embolized fistulous part of the AVM.

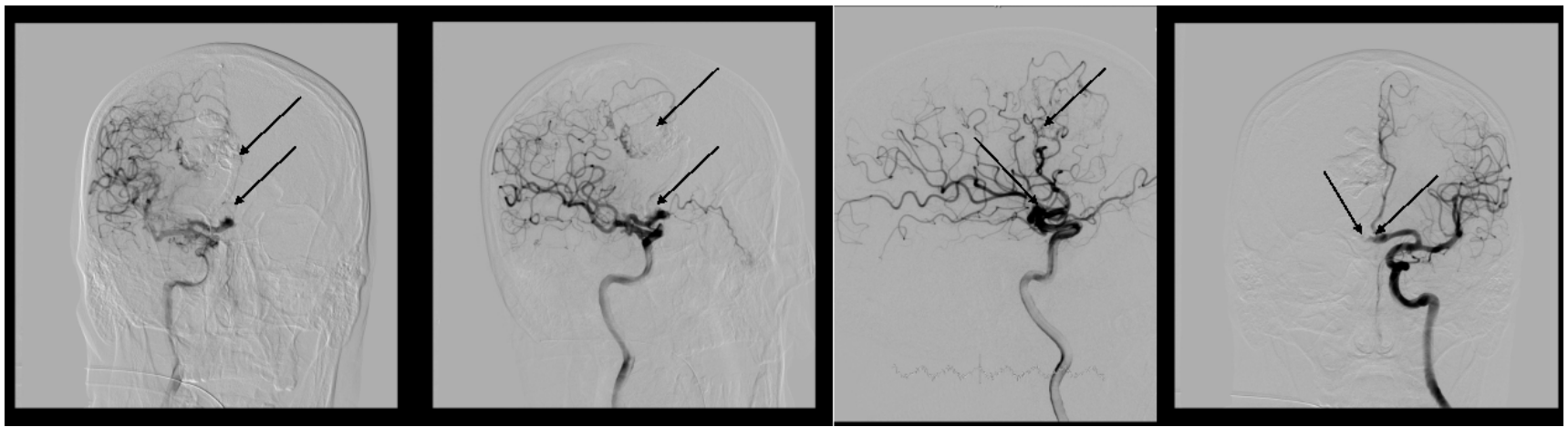

Figure 4: Control cerebral angiography showing embolized AVM and flow-related aneurysm. Left ICA. Blood flow in ACoA preserved.

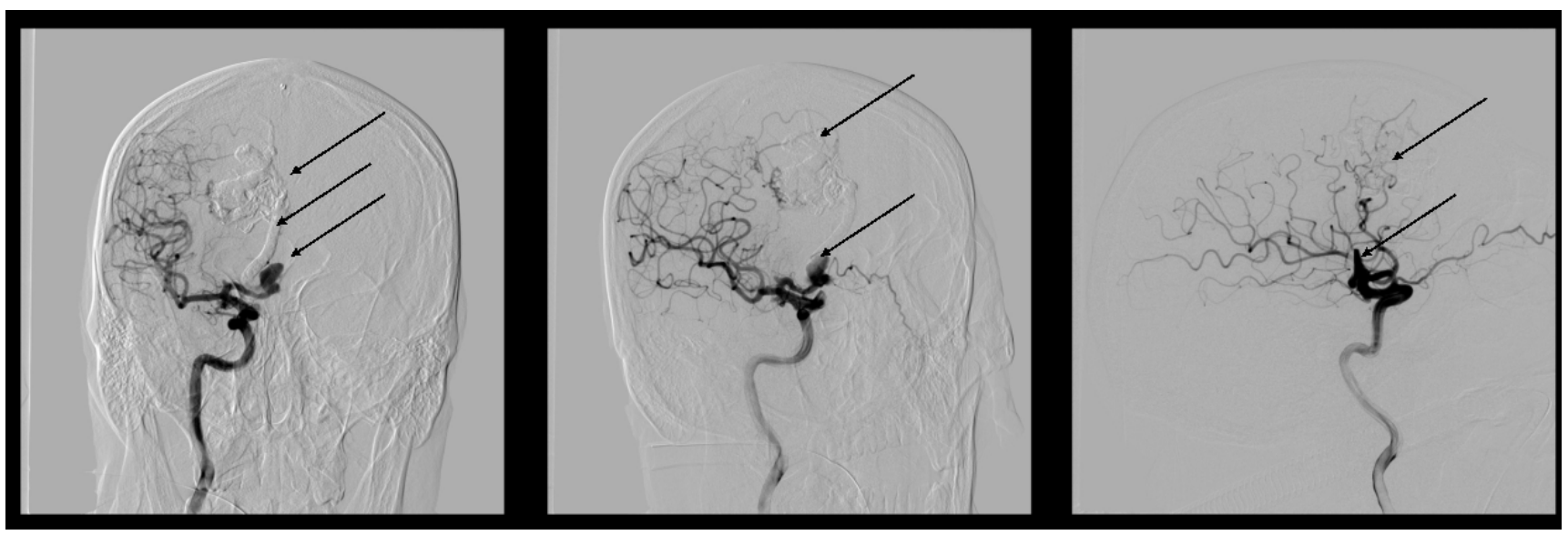

Figure 5: Control cerebral angiography showing embolized AVM, and flow-related aneurysm.

raphy and embolization of the AVM node with three doses of liquid embolic agent PHIL ${ }^{\circledR} 25 \%$ (MicroVention) (Figure 3). Then performed control angiography (Figure 4).

The second stage was the microcatheter Sonic ${ }^{\circledR}$ (BALT) $1.5 \mathrm{~F}$ is wound up in the cavity of the aneurysm, positioned in the area of the dome. Inflated balloon on a guide catheter Corail $+{ }^{\circledR}$ (BALT) $6 \mathrm{~F}$ during embolization. Blood pressure is reduced to $80 / 60$ $\mathrm{mmHg}$, embolization is performed. After embolization the balloon on the guide catheter was deflated. On control angiography, we have found a good result: Subtotally embolized AVM and completely "turned off" aneurysm while preserving the anterior connect- 


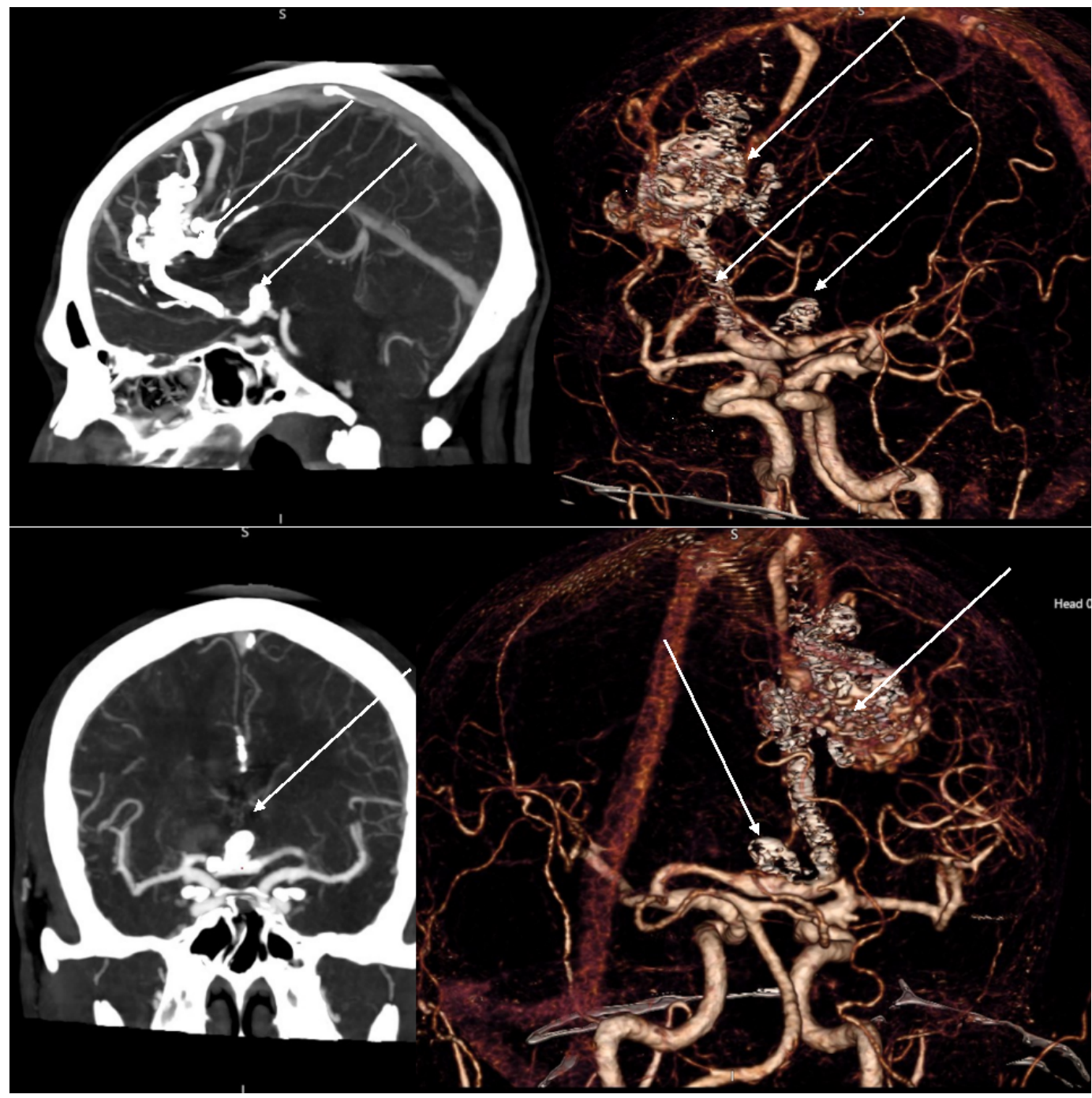

Figure 6: CT - angiography control showing subtotally embolized AVM and flow-related aneurysm.

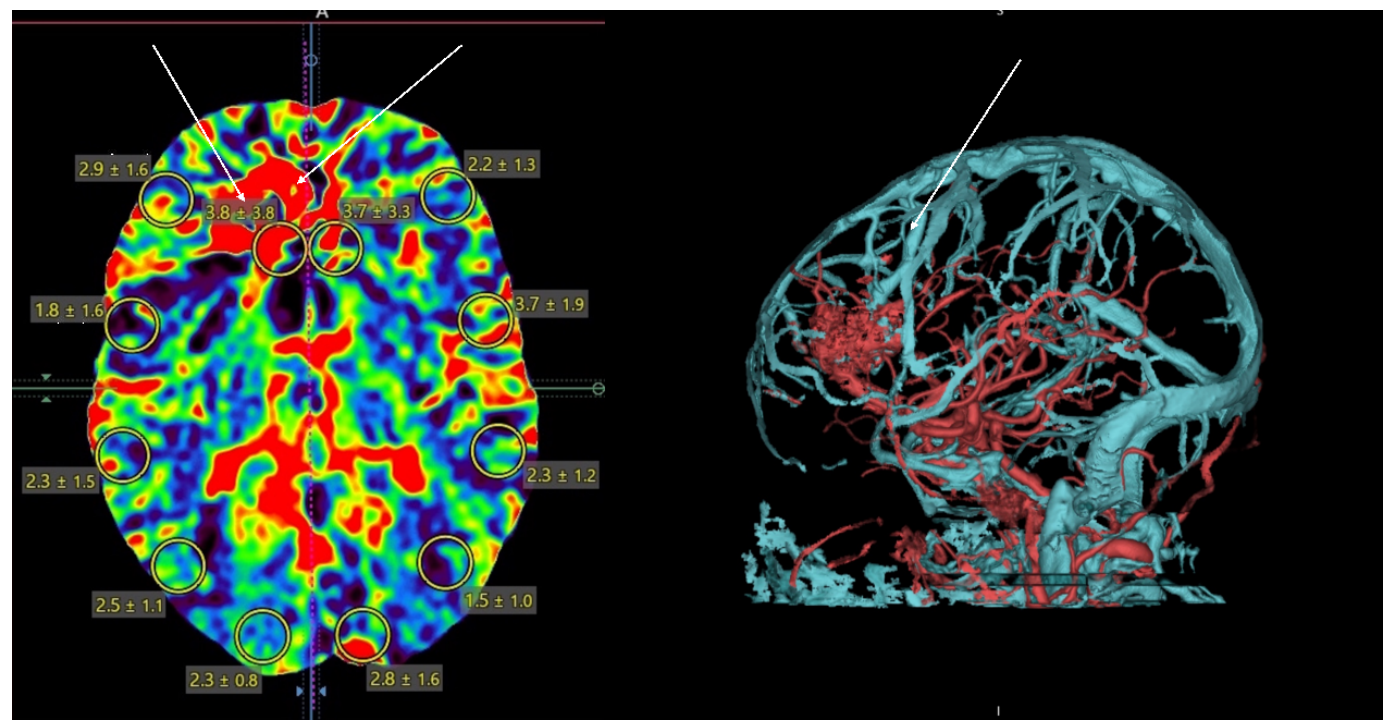

Figure 7: CT - perfusion showing hypoperfusion zone in the area of AVM and normal flow in drainage vein.

ing artery (ACoA) (Figure 5).

Microcatheter removed without technical difficulties. Endovascular instrumentation removed. Hemostasis of the puncture site. A pressure bandage was applied to the puncture site.
We performed control CT - angiography (Figure 6) and perfusion (Figure 7) after an hour to evaluate the volume of the embolized AVM site and identify the potentially dangerous rupture zones during blood flow distribution. According to CT - perfusion, there was a signif- 


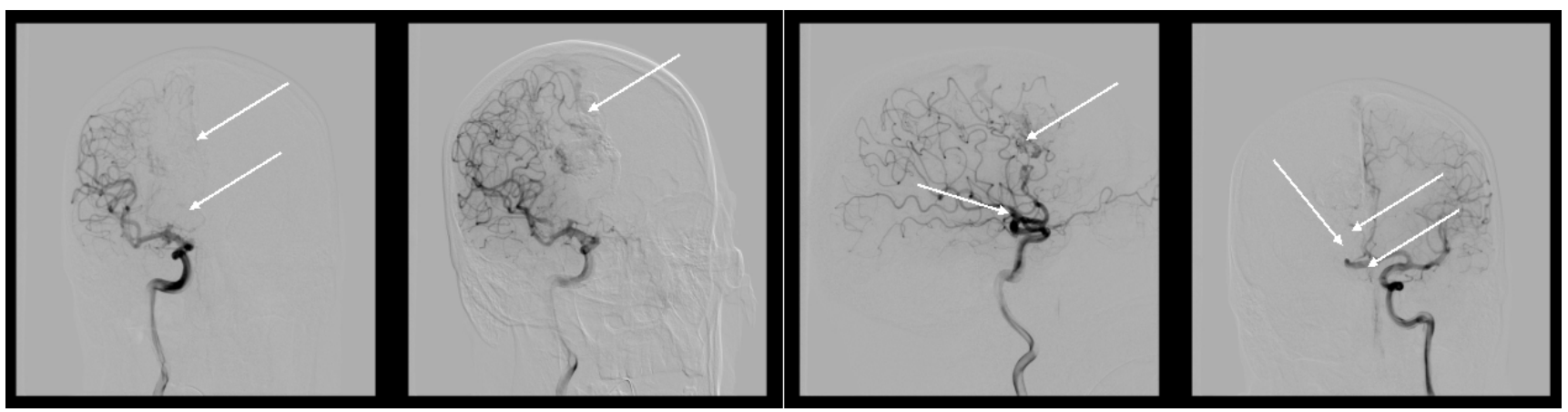

Figure 8: Cerebral angiography: AVM and aneurysm are not determined and the right recurrent artery of Heubner is normal.

icant decrease in perfusion in the AVM node in comparison with the previous CT - perfusion. Normalization of blood flow in the draining vein is also noted.

The early postoperative period was uneventful. Neurological status of the patient without features. The patient was discharged in good condition on the $3^{\text {rd }}$ day after the intervention.

After a month, the patient underwent control cerebral angiography (Figure 8). We noted good angiographic and clinical results.

\section{Discussion}

In patients with unruptured AVMs, the treatment strategy of the associated aneurysm(s) follows the criteria applied to the treatment of unruptured incidental aneurysms in general, with the caveat that some aneurysms hemodynamically connected to the AVM may decrease in size or even disappear after treatment of the AVM. In one study, which analyzed the fate of untreated aneurysms associated with AVMs after treatment of the AVM, 4 of the 5 (80\%) distal flow-related aneurysms disappeared after complete excision of the AVM, and only $1(20 \%)$ was unchanged. There were no instances of SAH from a flow-related aneurysm after AVM cure during the follow-up period (7.4 years). Instead, of the 23 proximal aneurysms, $18(78.3 \%)$ were unchanged, $4(17.4 \%)$ were smaller, and only $1(4.3 \%)$ regressed completely after treatment of the AVM. Because distal flow-related arterial aneurysms more often resolve or decrease in size after effective AVM treatment compared with other types of aneurysms, conservative management of small distal aneurysms may be indicated if the AVM is treated [17].

In our case, we have had a ruptured AVM and unruptured flow-related aneurysm on a large terminal afferent. Taking into account the data of CT - angiography, CT - perfusion and cerebral angiography, we chose the strategy of simultaneous embolization of AVM and flow-related aneurysm in order to minimize hemorrhagic complications. The use of CT - perfusion after the intervention allowed us to adequately assess the result of the treatment, evaluate the degree of hypoperfusion in the AVM area, note the areas of residual AVM component which are potentially dangerous for rupture, and select the appropriate conservative therapy.

\section{Conclusion}

The clinical case showed the efficacy and safety of using low-viscosity liquid embolic agents, not only for embolization of AVMs, but also for the proximal flow-related aneurysm.

Modern diagnostic capabilities allow us to adequately plan the strategy and tactics of treating AVM.

In our opinion, the use of a liquid embolic agent for embolization of the proximal flow-related aneurysm is justified only in cases where the aneurysm is localized on the AVM terminal afferents, and there is no high risk of distal embolism by the liquid embolic agent.

\section{References}

1. Stapf C, Mast $H$, Sciacca RR, Berenstein A, Nelson PK, et al. (2003) New york islands avm study collaborators. The new york islands avm study: Design, study progress, and initial results. Stroke 34: 29-33.

2. Brown RD, Fleming KD (2005) Natural history \& management of intracranial vascular malformations. Mayo clinic proc 80: 269-281.

3. Caldarelli M, Di Rocco C, lannelli A, Rollo M, Tamburrini G, et al. (1997) Combined management of intracranial vascular malformations in children. Neurosurg Sci 41: 315-324.

4. Graf CJ, Perret GE, Torner JC (1983) Bleeding from cerebral arteriovenous malformations as part of their natural history. J Neurosurg 58: 331-337.

5. Gross BA, Du R (2013) Natural history of cerebral arteriovenous malformations: A meta-analysis. J Neurosurg 118: 437-443.

6. Perret G, Nishioka H (1966) Report on the cooperative study of intracranial aneurysms and subarachnoidal hemorrhage. Section VI Arteriovenousmalformations. J Neurosurg 25: 467-490.

7. Brown RD, Wiebers DO, Forbes G, O'Fallon WM, Piepgras DG, et al. (1988) The natural history of unruptured intracranial arteriovenous malformations. J Neurosurg 68: 352-357.

8. Stapf C, Mohr JP, Pile-Spellman J, Sciacca RR, Hartmann A, et al. (2002) Concurrent arterial aneurysms in brain arteriovenous malformations with haemorrhagic presentation. $J$ Neurol Neurosurg Psychiatry 73: 294-298. 
9. Brown RD Jr, Wiebers DO, Forbes GS (1990) Unruptured intracranial aneurysms and arteriovenous malformations: frequency of intracranial hemorrhage and relationship of lesions. J Neurosurg 73: 859-863.

10. Abla AA, Nelson J, Rutledge WC, Young WL, Kim H, et al. (2014) The natural history of AVM hemorrhage in the posterior fossa: Comparison of hematoma volumes and neurological outcomes in patients with ruptured infra-and supratentorial AVMs. Neurosurg Focus 37: E6.

11. Da Costa L, Thines L, Dehdashti AR, Wallace MC, Willinsky RA, et al. (2009) Management and clinical outcome of posterior fossa arteriovenous malformations: Report on a single-centre 15-year experience. J Neurol Neurosurg Psychiatry 80: 376-379.

12. Gross BA, Ropper AE, Du R (2013) Vascular complications of stereotactic radiosurgery for arteriovenous malformations. Clin Neurol Neurosurg 115: 713-717.

13. Platz J, Berkefeld J, Singer OC, Wolff R, Seifert V, et al. (2014) Frequency, risk of hemorrhage and treatment con- siderations for cerebral arteriovenous malformations with associated aneurysms. Acta Neurochir (Wien) 156: 20252034.

14. van Beijnum J, van der Worp HB, Buis DR, AI-Shahi Salman R, Kappelle LJ, et al. (2011) Treatment of brain arteriovenous malformations: A systematic review and meta-analysis. JAMA 306: 2011-2019.

15. Mohr JP, Parides MK, Stapf C, Moquete E, Moy CS, et al. (2014) Medical management with or without interventional therapy for unruptured brain arteriovenous malformations (ARUBA): A multicentre, non-blinded, randomised trial. Lancet 383: 614-621.

16. Kim EJ, Halim AX, Dowd CF, Lawton MT, Singh V, et al. (2004) The relationship of coexisting extranidal aneurysms to intracranial hemorrhage in patients harboring brain arteriovenous malformations. Neurosurgery.

17. Gardenghi B, Bortolotti C, Lanzino G, HJ Cloft, SK Rammos (2014) Aneurysms associated with arteriovenous malformations. Contemporary Neurosurgery 36. 